\title{
EUNACOM: un esfuerzo señero de las Facultades de Medicina Chilenas
}

\author{
LUIS IBÁÑEZ A. ${ }^{1}$ \\ 1. Presidente de ASOFAMECH. Decano Facultad de Medicina, Universidad Católica
}

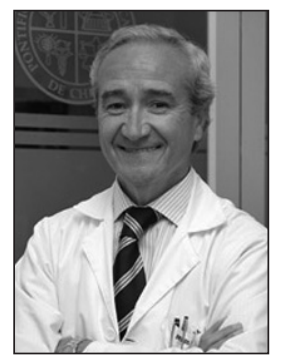

Las Facultades de Medicina de Chile han tenido una constante preocupación por la calidad de lo que enseñan. Así, fueron pioneras en el desarrollo de la acreditación universitaria y las primeras en establecer un examen que midiera los conocimientos de los egresados: el Examen Médico Nacional, que se tomó por primera vez en 2003.

El objetivo para el cual fue creado este examen era obtener una cierta homologación de las dispares calificaciones que los egresados obtenían, dependiendo de la Escuela de Medicina de la cual egresaran, de esta forma sería más justo al momento de asignar becas y concursos. El examen era voluntario y poco a poco se fue prestigiando entre los estudiantes. En su construcción participaban especialistas de las distintas facultades para generar los contenidos de las preguntas y expertos en educación que evaluaban la construcción de las mismas. Todo marchó bien, el prestigio del examen creció y lo transformó en un ejemplo para otras profesiones.

En 2009, y por Ley de la República, el examen pasó a llamarse Examen Único Nacional de Conocimientos en Medicina (EUNACOM), y se hizo obligatorio para quienes desearan trabajar en cargos estatales, de salud municipal, otorgar prestaciones a beneficiarios de FONASA o postular a programas de especialización médica. Las Facultades de Medicina nunca solicitaron que el examen se hiciera obligatorio ni buscaron el concepto de aprobación/reprobación, que fue introducido en dicha ley. Tampoco transformar el examen en habilitante para profesionales extranjeros, lo que obligó a agregar una sección práctica que garantizara el dominio de competencias básicas de profesionales cuyo proceso de formación era muy heterogéneo.

Entre otros vacíos, la ley no consideró recursos económicos para solventar el examen, ni definió delitos para eventuales actuaciones deshonestas en la elaboración del examen.

Al convertirse el examen en un requisito para buena parte de los empleos médicos, aumentó la presión sobre el instrumento, alejándolo de los objetivos para los que fue creado. Aunque ASOFAMECH publicó los resultados por escuela como un elemento básico de transparencia, los medios le dieron fuerte énfasis a este aspecto, identificando en la opinión pública la calidad de las Escuelas con el resultado obtenido en el examen, lo que generó molestia en las facultades.

A pesar de estas dificultades, todo funcionó bien hasta la versión de 2012, en la cual se denunció la filtración de varias preguntas, producto de la conducta deshonesta de algunos profesores, que memorizaron algunos temas y preguntas y los entregaron a ciertos estudiantes. Todo este triste episodio provocó alarma pública y llevó a cuestionar todo el brillante desarrollo del examen. Paradojalmente, más que criticar la deshonestidad de quienes filtra- 
ron contenidos, el cuestionamiento se centró sobre el examen mismo.

La ASOFAMECH apoya firmemente la existencia de un examen médico nacional, pues es consciente de su responsabilidad social principal, la calidad de la formación médica. Con el fin de establecer las correcciones que permitieran mantener el examen conformó un grupo de trabajo integrado por los estudiantes, el Ministerio de Salud, el Colegio Médico y la misma ASOFAMECH. Este grupo ha pro- puesto el traspaso del examen a una agencia independiente con financiamiento público $\mathrm{y}$, a la luz de la investigación de los hechos, ha definido los cambios necesarios para evitar nuevas filtraciones.

Son las conclusiones de esta comisión las que esperamos compartir con el Estado, para generar esta renovada fase de EUNACOM, un orgullo para las Facultades de Medicina y uno de sus mayores aportes para garantizar la calidad de la Educación Superior Chilena. 